\title{
ANÁLISE DE DADOS HIPERESPECTRAIS EM MINA DE MANGANÊS LATERÍTICO, SÃO JOÃO DA ALIANÇA (GO)
}

\author{
Osmar Abílio de Carvalho Júnior ${ }^{1}$, Múcio Nobre da Costa Ribeiro², Éder de Souza Martins ${ }^{3}$, \\ Edi Mendes Guimarães ${ }^{4}$, Paulo Roberto Meneses ${ }^{5}$ e Renato Fontes Guimarães ${ }^{1}$
}

Recebido em 30 abril, 2007 / Aceito em 28 junho, 2007

Received on April 30, 2007 / Accepted on June 28, 2007

\begin{abstract}
The aim this paper is to develop a methodology of lateritic manganese identification using imaging spectroscopy. In this study was used the Airborne Visible/InfraRed Imaging Spectrometer (AVIRIS) image. The AVIRIS is an imaging sensor that measures the solar reflected spectrum from $400 \mathrm{~nm}$ to $2500 \mathrm{~nm}$ at 10 $\mathrm{nm}$ intervals. The study area is located at Goiás State and enclosed the Fazenda Extrema mine that presents lateritic manganese deposits developed on Paranoá Group rocks. Laboratory spectrometry studies conjugated with mineralogical analysis by diffractometry of $\mathrm{X}$-ray demonstrated that the ore spectrum is opaque and spectrally featureless, due to the conduction band of $\mathrm{MnO}_{3}$ extending throughout this spectral range. The digital image processing can be subdivided in the following steps: (a) atmospheric correction using Green method, (b) areas selection with opaque behavior from the integral spectra calculation, and (c) lateritic manganese individualization using the Minimum Noise Fraction transformation. The method is efficient to classify areas of abandoned manganese mine that consist of priority areas for implementation of environmental recovery.
\end{abstract}

Keywords: spectral mixture, hyperspectral; imaging spectroscopy, manganese, laterite.

RESUMO. 0 objetivo do presente trabalho foi desenvolver uma metodologia para identificação de lateritas manganesíferas por espectroscopia de imageamento. Nesse estudo foi utilizada a imagem do Airborne Visible/InfraRed Imaging Spectrometer (AVIRIS). 0 AVIRIS é um sensor que mede o espectro solar refletido de $400 \mathrm{~nm}$ para $2500 \mathrm{~nm}$ em intervalos de $10 \mathrm{~nm}$. A área de estudo localiza-se no Estado de Goiás e engloba a mina Fazenda Extrema que apresenta depósitos de manganês desenvolvido nas rochas do Grupo Paranoá. Estudos de espectrometria de laboratório, conjugado com análise mineralógica por difratometria de raios-X, demonstram o caráter opaco do espectro do minério que não apresentam feições de absorção distintas devido à banda de condução do $\mathrm{MnO}_{3}$ que se estende por todo 0 intervalo espectral. Visando explorar essa característica foi desenvolvida uma metodologia para o processamento digital de imagem contendo três etapas: (a) correção atmosférica pelo método Green, (b) seleção das áreas com comportamento opaco pelo cálculo da integral do espectro, e (c) individualização das áreas com presença de lateritas manganesíferas entre os alvos de baixo albedo utilizando a transformação por Minimum Noise Fraction. 0 procedimento desenvolvido mostrou ser eficiente na classificação de áreas de mina de manganês abandonadas que consistem em áreas prioritárias para recuperação ambiental.

Palavras-chave: mistura spectral, hiperespectral, espectroscopia de imageamento, manganês, laterita.

\footnotetext{
1 Universidade de Brasília, Departamento de Geografia, Campus Darcy Ribeiro Asa Norte - 70910-900 Brasília, DF, Brasil. Tel.: (61) 3307-1859; Fax: (61) 3272-1909 -E-mails: osmarij@unb.br; renatofg@unb.br

${ }^{2}$ Fundação Nacional do Índio, FUNAI, Departamento de Patrimônio Indígena e Meio Ambiente, Depima, EQS 702/902, Ed. Lex, 3 andar Brasília, DF, Brasil. Tel.: (61) 3313-3539/3537; Fax: (61) 3223-9281 - E-mail: mucio@funai.gov.br

3 Empresa Brasileira de Pesquisa Agropecuária, Centro de Pesquisa Agropecuária dos Cerrados, CPAC, BR 020, km 18, Rod. Brasília-Fortaleza, Pedologia, Planaltina, Caixa Postal 08223 - 73301-970 Brasília, DF, Brasil. Tel.: (61) 3388-9870; Fax: (61) 3388-9879 - E-mail: eder@cpac.embrapa.br

${ }^{4}$ Universidade de Brasília, Instituto de Geociências, Departamento de Mineralogia e Petrologia, UnB-ICC-Ass370, Laboratório de Raios-X, 70910-900 Brasília, DF, Brasil. Tel.: (61) 3307-2438; Fax: (61) 3347-4062 - E-mail: rxrdi@unb.br

${ }^{5}$ Universidade de Brasília, Instituto de Geociências, Departamento de Geologia Geral e Aplicada, Campus Darcy Ribeiro Asa Norte, Caixa Postal 4465 - 70910-900 Brasília, DF, Brasil. Tel.: (61) 3307-2433 Ramal 2872; Fax: (61) 3347-4062 -E-mail: pmeneses@unb.br
} 


\section{INTRODUÇ̃̃̃O}

As áreas cratônicas em zonas tropicais favorecem a acumulação de metais em depósitos lateríticos devido às suas condições climáticas com elevadas pluviosidade e temperatura. No Brasil, as lateritas cobrem aproximadamente $65 \%$ do território (Melfi et al., 1988), o que torna de grande importância 0 desenvolvimento de metodologias, tanto na prospecção de novos depósitos, como na identificação de minas abandonadas que devem ser recuperadas. Neste contexto, o sensoriamento remoto consiste em uma importante ferramenta para 0 mapeamento mineral (Rajesh, 2004), por permitir levantar áreas extensas com baixos custos e em intervalo de tempo relativamente pequeno.

Dentre os sensores ópticos desenvolvidos, os sensores hiperespectrais permitem obter uma maior acurácia na identificação mineralógica por permitir gerar curvas espectrais com resolução compatíveis com as de laboratório. A espectrometria de imageamento é capaz de adquirir espectros praticamente contínuos ao longo da porção do espectro solar refletido, ou seja, de 0,4 a $2,5 \mu \mathrm{m}$ (Vane et al., 1984). Um dos principais sensores hiperespectrais em operação é 0 Airborne Visible/Infrared Imaging Spectrometer (AVIRIS) desenvolvido em 1983 pela National Aeronautics and Space Administration (NASA) (Fig. 1). 0 desenvolvimento do projeto teve início em 1984, porém os primeiros vôos experimentais só começaram em 1987 (Vane \& Goetz, 1988). 0 AVIRIS tornou-se operacional em 1989, após alguns ajustes e correções realizadas pelos pesquisadores do Jet Propulsion Laboratory (JPL), NASA. 0 sensor possui quatro espectrômetros: A, B, C e D, com os seguintes intervalos nominais: A $(0,4$ a $0,7 \mu \mathrm{m}), \mathrm{B}(0,65$ a $1,25 \mu \mathrm{m}), \mathrm{C}(1,2$ a $1,82 \mu \mathrm{m})$ e D (1,78 a $2,40 \mu \mathrm{m}) .0$ AVIRIS gera uma imagem com resolução espectral aproximadamente de 10 nanômetros (nm) e possui 224 bandas.

0 instrumento voa a bordo da aeronave ER-2 da NASA, a uma altura aproximada de $20 \mathrm{~km}$ acima do nível do mar e com uma velocidade aproximada de $730 \mathrm{~km} / \mathrm{h}$. Essas aeronaves possuem algumas vantagens como: a) a estabilidade em vôo - que gera boa geometria de imageamento e evita a reamostragem de dados espectrométricos; b) possuem baixa relação velocidade/altura $(\mathrm{V} / \mathrm{H})$, com taxa de varredura mais lenta, o que melhora a relação sinal ruído; e c) podem obter dados locais de até $2.100 \mathrm{~km}$ de extensão em um único vôo o que facilita a obtenção de dados de grandes áreas. Nos últimos anos o sensor AVIRIS sobrevoou os EUA, Canadá, Brasil e Europa.

O AVIRIS foi trazido para o Brasil em 1995 na missão SCAR-B (Smoke, Clouds and Radiation - Brazil), que teve como propósito 0 estudo dos constituintes da atmosfera. Essa atividade foi uma operação conjunta da NASA, Instituto Nacional de Pesquisas Espaciais (INPE) e a Agência Espacial Brasileira (AEB) (Kaufman et al., 1998). Nesse levantamento, foi realizado um sobrevôo sobre 0 depósito de manganês laterítico na mina Extrema em São João da Aliança (GO). Este depósito, como vários outros na região, encontra-se abandonado e consiste em uma importante área para recuperação ambiental.

0 presente trabalho possui como objetivo avaliar e desenvolver técnicas de processamento de imagens hiperespectrais do sensor AVIRIS para a identificação de áreas relativas à presença de manganês supergênico tanto para fins prospectivos como para identificação de áreas que devem ser ambientalmente recuperadas.

\section{ÁREA DE ESTUDO}

A área de estudo localiza-se na porção central do estado de Goiás, entre os municípios de São Gabriel de Goiás e Alto Paraíso de Goiás. 0 acesso rodoviário pode ser feito a partir de Brasília pela BR 020 (Brasília-Fortaleza) seguindo pela rodovia G0-118 até São João D'Aliança onde percorre por estrada vicinal aproximadamente 6,5 km para nordeste (Fig. 2).

Os depósitos manganesíferos ocorrem sobre as rochas do Grupo Paranoá, associados a processos de lateritização. 0 Grupo Paranoá é composto essencialmente por rochas de baixo grau metamórfico formadas por sedimentação detrítica de margem passiva, com contribuição de calcários e dolomitos em sua porção média e superior, afetados pelo ciclo orogênico Brasiliano (Dardenne, 1979; Faria, 1995). Nesta região, 0 Grupo Paranoá sobrepõe o Grupo Araí, em discordância angular, na porção sul do Parque Nacional da Chapada dos Veadeiros, G0, estendendose para 0 sul, ao longo da Serra Geral do Paranã (Faria, 1995).

As principais jazidas neste ambiente geológico são a de Pedra Preta, Fortaleza, Buritizinho e Fazenda Extrema caracterizadas por Baeta Júnior et al. (1978). Além dessas, são conhecidos mais seis depósitos de manganês de pequeno porte que tiveram atividade exploratória: Palmeiras, Fraternidade, São Lourenço e São João, Vereda e Vãozinho.

A jazida da Fazenda Extrema é a mais próxima da cidade de São João D'Aliança. Está localizada na base de uma encosta, cujo topo é sustentado por horizonte mosqueado desenvolvido sobre saprólito de metassiltito, de coloração avermelhada. A superfície onde se situa a antiga jazida inclina-se suavemente para o norte, até 0 leito do Córrego Extrema, com extensão aproximada de $1 \mathrm{~km}$, constituindo-se em uma zona de relevo moderado.

A mineralização está situada na base da Formação São João 
Cada pixel apresenta um espectro contínuo que é usado para analisar a superfície e atmosfera

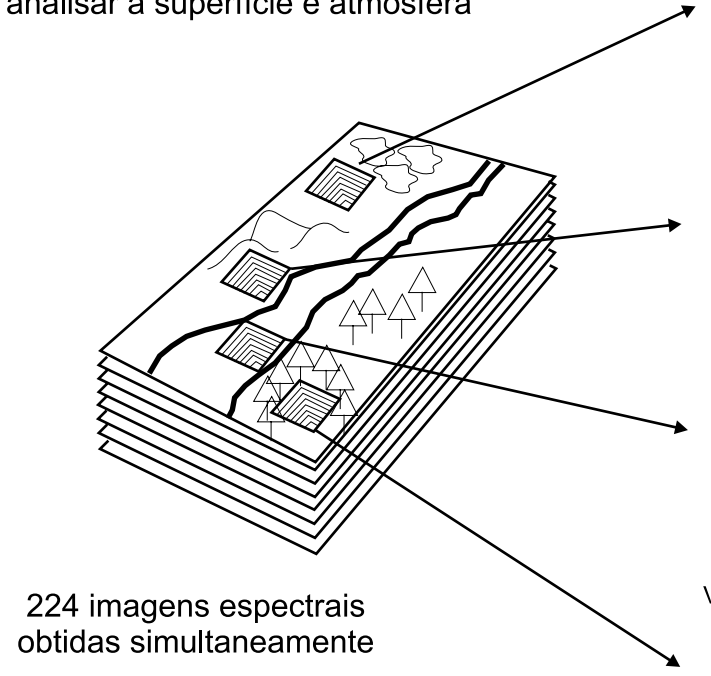

Atmosfera
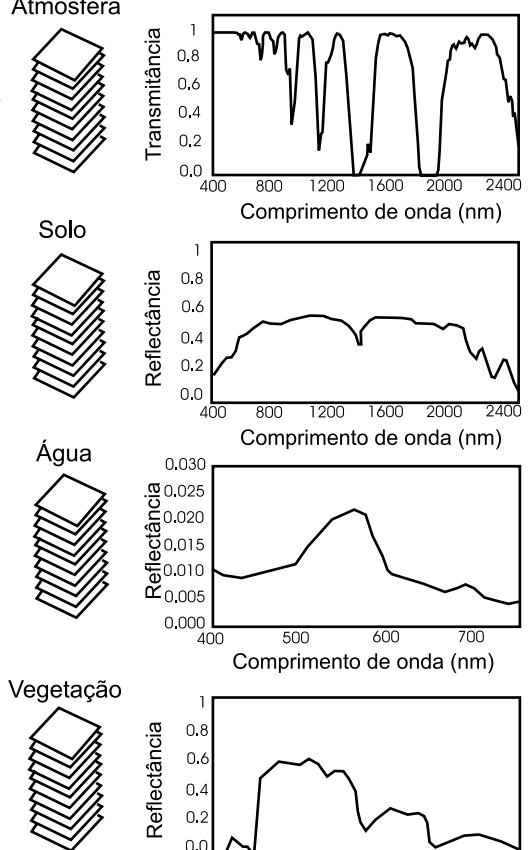

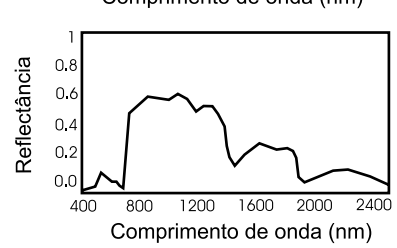

Figura 1 - Concepção do sensor hiperespectral AVIRIS desenvolvido pelo Laboratório do JPL/NASA (Fonte: Green et al., 1998).

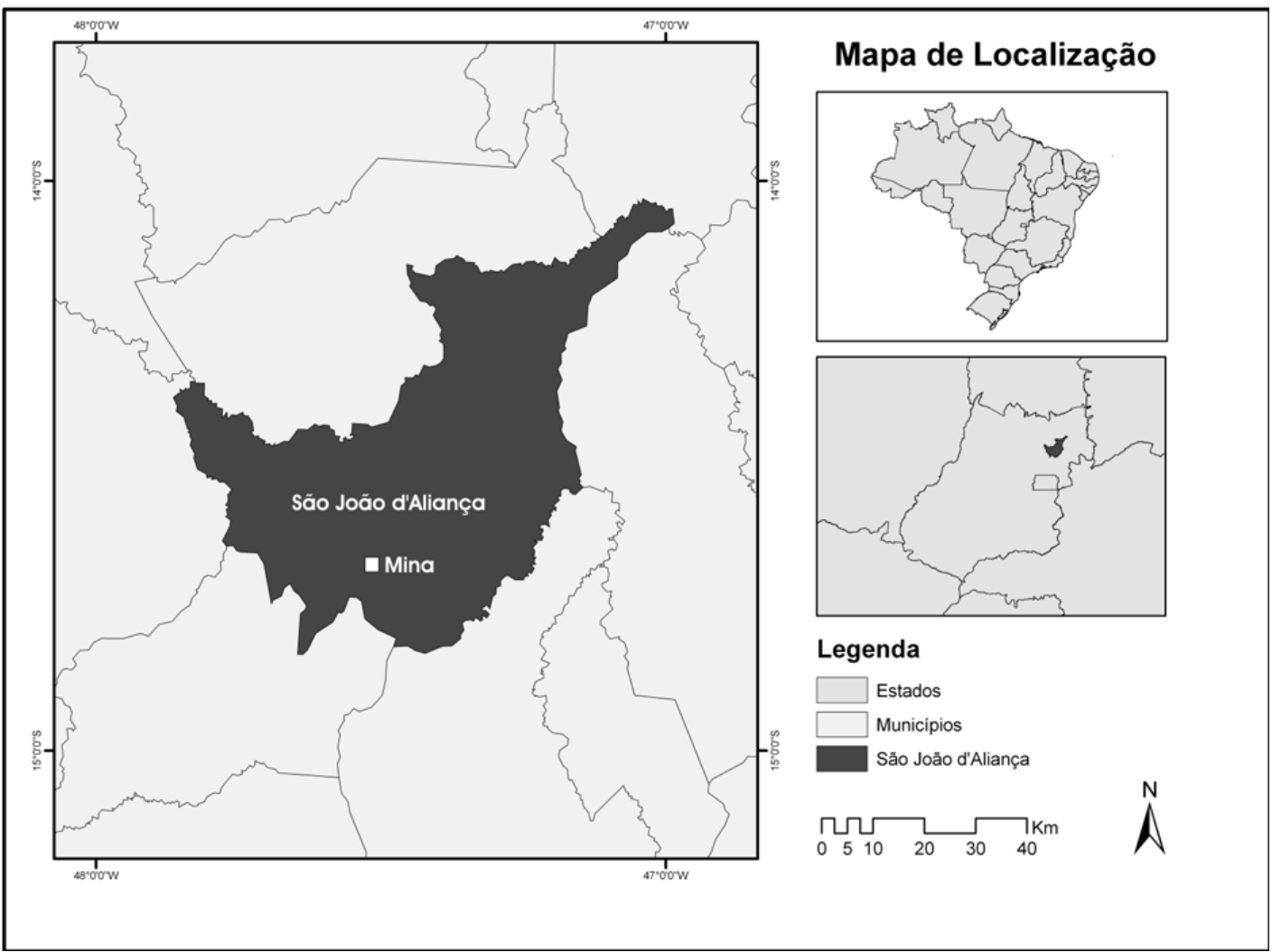

Figura 2 - Mapa de localização da área de estudo. 
D’Aliança, do Grupo Paranoá. 0 perfil laterítico simplificado apresenta três horizontes principais: horizonte ferruginoso, saprólito argiloso e o nível com minério de manganês laterítico (Fig. 3).

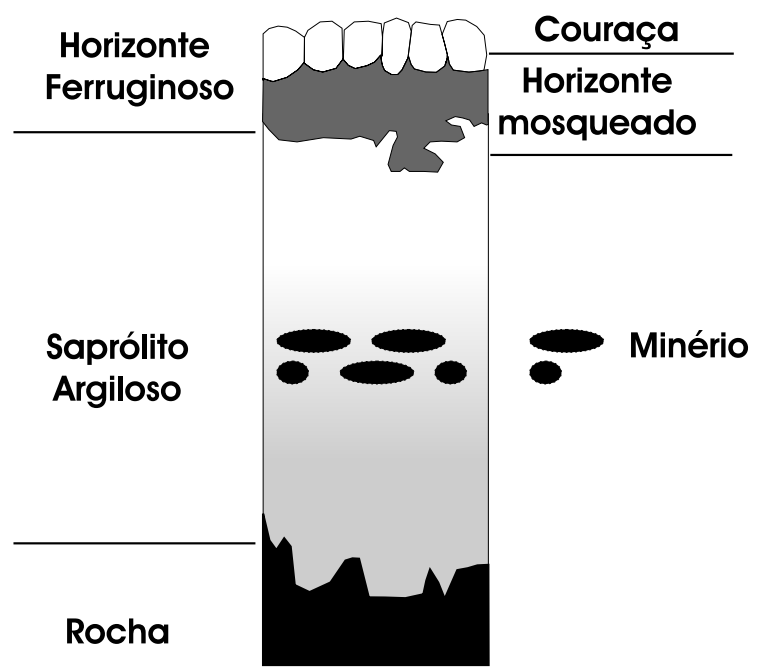

Figura 3 - Perfil de intemperismo presente na jazida da Fazenda Extrema.

0 horizonte ferruginoso pode ser subdividido em dois níveis: couraça e mosqueado. 0 nível mosqueado ocorre na base do horizonte ferruginoso e possui uma estrutura terrosa de coloração amarelada com manchas e vênulas de coloração vermeIha para violeta, ainda com feições do saprólito preservadas em algumas porções. Este nível é constituído por caulinita, gibbsita, quartzo e oxi-hidróxidos de ferro (hematita e goethita) nas manchas marrom-avermelhadas. No topo do horizonte ferruginoso há uma couraça ferruginosa descontínua, na forma de blocos e nódulos ferruginosos, imersos em matriz terrosa e argilosa. Os nódulos endurecidos da couraça são constituídos principalmente por goethita e hematita em matriz argilosa caulinítica.

0 saprólito argiloso é proveniente do intemperismo de ardósia e metassiltitos, caracterizado por colorações claras (esverdeada, rósea e violácea). As camadas possuem uma direção entre N15-50 $\mathrm{E}$, com mergulho máximo de $20^{\circ} \mathrm{NW}$, constituindo uma estrutura homoclinal. Pode também conter delgados leitos de quartzito muito fino, de cores claras. A mineralogia deste horizonte é dominada por caulinita e illita, sendo subsidiário oxihidróxidos de Fe e Mn.

Constata-se na base do saprólito argiloso a presença de estruturas primárias preservadas que é destruída progressivamente para o topo pelo aumento da presença de óxidos e hidróxidos de ferro e minerais de argila que dominam a matriz. Observa-se a presença de fraturas que acompanham planos de acamamento das ardósias preenchidas com óxidos de manganês e ferro de cor castanho escuro.
0 minério de manganês laterítico foi classificado como sendo de pequeno porte estando presente de forma dispersa no saprólito, como grãos, seixos, matacões e bloco de minério maciço, não apresentando um corpo de minério. Na área do depósito, já explorado nos seus níveis mais ricos, ainda apresentam vestígios dos horizontes lateríticos lavrados, com porções remanescentes de minério de manganês e couraça ferruginosa. A área mineralizada possui dimensão aproximada de 15 ha e espessura máxima de $4 \mathrm{~m}$. A presença de uma estrada secundária subdivide a antiga mina de manganês em duas porções.

Os estudos de Guimarães (1978) para os principais jazimentos da região demonstram que a formação do minério laterítico ocorreu a partir da lixiviação de íons de K, Mg, Ca e Na, e concentrados $\mathrm{Fe}, \mathrm{Al}, \mathrm{Mn}$ e em parte o $\mathrm{Si}$, que permanecem como minerais neoformados. Essa acumulação de óxidos e hidróxidos de Fe e Mn resulta de movimentos verticais de soluções e em particular da migração lateral do lençol freático no interior do perfil. 0 Fe e Mn nos estados reduzidos formam complexos orgânicos e inorgânicos estáveis, permanecendo em solução no meio úmido e precipitam bruscamente, sob a forma de óxidos e hidróxidos de $\mathrm{Fe}^{+3}, \mathrm{Mn}^{+3}$ e $\mathrm{Mn}^{+4}$, em meio seco ou em zonas de oxidação. A separação entre estes dois elementos é função do potencial redox local, em ambiente de mesmo pH, o ferro se precipita em condições de Eh mais baixo.

\section{MATERIAIS E MÉTODOS}

\section{Análise radiométrica do perfil de intemperismo}

A detecção e estimativa de abundância mineral utilizando métodos de radiometria na faixa do visível e infravermelho próximo apresenta como vantagem a rapidez da aquisição da informação e a não destruição da amostra. Devido à alta portabilidade dos espectrorradiômetros de campo pode-se realizar um acompanhamento mineralógico no próprio local de extração, reduzindo 0 tempo e priorizando amostras para análise em laboratório. Além disso, com o avanço da espectroscopia de imageamento podese ter um acompanhamento da distribuição mineral em planta das minas de céu aberto utilizando técnicas de processamento digital.

$\mathrm{Na}$ área de estudo a análise radiométria foi feita a partir de amostras referentes aos horizontes lateríticos: horizonte ferruginoso, saprólito argiloso e do minério de manganês.

Inicialmente, as amostras foram secadas em estufa a $40^{\circ} \mathrm{C}$, desagregadas levemente com martelo de madeira e peneiradas em duas frações ( $>2 \mathrm{~mm}$ e outra $<2 \mathrm{~mm}$ ). As curvas espectrais das amostras foram obtidas utilizando um espectroradiômetro da 
marca GER (Geophysical and Environmental Research Corporation), modelo IRIS (Infrared Intelligent Spectroradiometer) MARK V. Este instrumento opera na faixa espectral de $300 \mathrm{a} 2500 \mathrm{~nm}$, com larguras de bandas de $2 \mathrm{~nm}$ no intervalo de 300 a $1000 \mathrm{~nm}$ e de $4 \mathrm{~nm}$, entre 1000 a $2500 \mathrm{~nm}$.

As amostras também foram analisadas por difratometria de raios-X, empregando o difratômetro Rigaku D-MAXB, e algumas amostras foram selecionadas para análise química total, empregando a espectrometria de emissão atômica com plasma de acoplamento induzido, ICP-EAS.

\section{Processamento digital da imagem hiperespectral}

Os principais métodos para classificação espectral dos componentes minerais utilizam um parâmetro de similaridade de feições de absorção. No entanto, os óxidos de manganês, a exemplo de outros minérios opacos, não apresentam feições típicas de absorção. Assim, os métodos tradicionais para classificação espectral como o Spectral Angle Mapper (SAM) (Kruse et al., 1993a, 1993b), Spectral Correlation Mapper (SCM) (Carvalho Júnior \& Meneses, 2000), Spectral Feature Fitting (SFF) (ENVI, 1997) e 0 coeficiente de correlação R do Tricorder (Clark \& Swayze, 1995) não mostram eficiência para a classificação desses minerais.

No presente trabalho a metodologia proposta para a detecção de prováveis áreas de depósitos de manganês a partir da espectrometria de imageamento é composta por três procedimentos: (a) correção atmosférica, (b) identificação de áreas com baixo albedo a partir do cálculo da integral do espectro; e (c) identificação e classificação espectral das áreas de baixo albedo pelo emprego do Minimum Noise Fraction (MNF) e análise espectral.

\section{Correção atmostérica}

A correção atmosférica da imagem AVIRIS foi realizada pelo método Green (1990) que proporciona uma estimava dos parâmetros atmosféricos e cálculo da reflectância aparente da superfície usando 0 código de transferência radiativa MODTRAN 3 (Berk et al., 1989; Anderson et al., 1995) em conjunto com um modelo de ajuste não linear por mínimos quadrados (Green et al., 1991, 1993). Esse algoritmo compensa os seguintes efeitos: (a) absorção dos gases da atmosfera; (b) espalhamento molecular e aerossol; (c) geometria de iluminação solar e geometria de visada da aeronave; e (d) comportamento atmosférico latitudinal e sazonal. No entanto, permanecem desconsiderados os parâmetros relativos aos ângulos da superfície incidente e emergente e a função da reflectância bidirecional. 0 método Green não considera os efeitos topográficos, assumindo que a superfície é horizontal com reflectância Lambertiana. Uma aproximação da topografia é obtida com o emprego do valor médio da altitude. 0 método Green apresenta melhores resultados que 0 método ATREM ATmosphere REMoval program - ATREM (Gao et al., 1993) também desenvolvido para a correção atmosférica de imagens hiperespectrais (Carvalho Júnior et al., 2002a).

A correção atmosférica da imagem AVIRIS pelo Método Green é obtida pela execução de quatro programas compilados em linguagem FORTRAN (H2OLUT, H2SPL, VLSFIT e RFL) (Latorre, 1998). Cada programa utiliza os resultados anteriores gerados acrescidos de novos parâmetros. Para cada etapa deve-se gerar um arquivo de entrada com todas as informações necessárias para a execução do programa. 0 método Green gera a imagem corrigida e uma seqüência de dez imagens denominadas de VLS (vapor, líquido e sólido). A Figura 4 apresenta espectros antes e depois da correção atmosférica aplicada pelo método Green, relativos a uma área de vegetação.

\section{Identificação de áreas de baixo albedo pelo cálculo da integral do espectro}

A principal característica dos espectros de minerais opacos é 0 baixo valor de albedo. Para realçar essa característica foi desenvolvido um método que calcula a integral do espectro em linguagem IDL. A integral do espectro ( $I E$ ) pode ser definida como o somatório da intensidade da reflectância $\left(R_{\lambda}\right)$ de cada banda multiplicada pela largura da banda $(L B)$ :

$$
I E=\sum R_{\lambda} \times L B_{\lambda}
$$

No entanto, esse procedimento acaba aglutinando dentro do mesmo grupo de baixo albedo outras áreas sem interesse como áreas sombreadas, corpos d'água entre outros. Para a área de estudo a maior interferência é proveniente das áreas sombreadas que contêm intensa cobertura vegetal em relevo acidentado. Com o propósito de diminuir essa interferência foi adaptada uma segunda formulação onde se destacam as áreas vegetadas com relação às áreas de mineração:

$$
\begin{aligned}
I E M= & \left(\sum_{0.82}^{1.28} R_{\lambda} \times L B_{\lambda}\right) \times \\
& \left(\sum_{1.47}^{1.77} R_{\lambda} \times L B_{\lambda}-\sum_{2.06}^{2.36} R_{\lambda} \times L B_{\lambda}\right)
\end{aligned}
$$

Esse índice (IEM) torna os valores das áreas de vegetação sombreadas mais altos do que as áreas com solos ricos em opacos. 

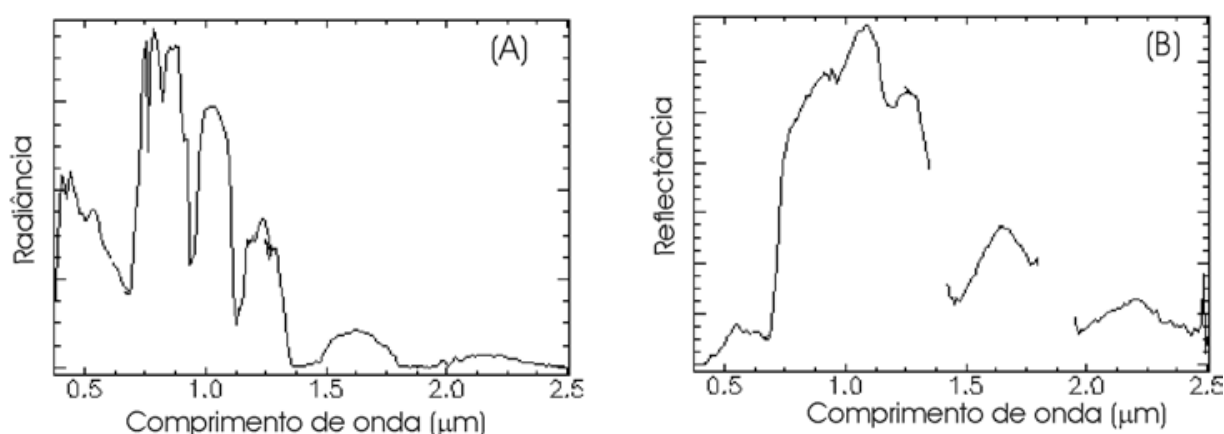

Figura 4 - Espectro do AVIRIS: (a) curva da radiância sem a correção atmostérica (b) curva de reflectância corrigida do efeito atmosférico.

A separação entre ambas pode ser obtida pelo fatiamento dos valores mais baixos da imagem gerada.

\section{Emprego da transformação MNF para áreas de baixo albedo}

Para localidades com maior complexidade de sombreamento e de misturas minerais pode-se complementar o tratamento com a análise específica para os pontos previamente determinados pelo emprego da integral. Uma forma de individualizar os diferentes alvos que compõe as áreas de baixo albedo é o emprego de uma técnica de redução espectral como a transformação Minimum Noise Fraction (MNF) restrito apenas para as áreas de baixo albedo.

0 método MNF foi proposto por Green et al. (1988), estando no âmbito da Análise de Principais Componentes (APC). Este método concilia tanto os procedimentos de segregação da componente ruído como também de redução da dimensionalidade dos dados, o que torna a técnica de caráter versátil. A principal diferença entre os métodos é que a APC prioriza a variância no ordenamento dos dados enquanto que a MNF prioriza a razão sinal/ruído. Assim sendo, a transformação por MNF permite um ordenamento de suas componentes conforme a qualidade da imagem (Green et al., 1988; Lee et al., 1990). 0 desenvolvimento matemático pode ser dividido em 4 etapas: (1) obtenção de uma amostra do ruído e cálculo de sua matriz de covariância, (2) estabelecimento de um índice de fracionamento do ruído, (3) implementação da função de transformação linear nos moldes da APC e (4) inversão do procedimento do MNF considerando apenas a fração do sinal (Carvalho Júnior et al., 2002b).

A distribuição espacial dos atributos espectrais das componentes MNFs pode ser observada pelo emprego do visualizador $n$-dimensional no programa ENVI que gera uma nuvem de pontos referente às células com espectro de baixa reflectância. Esse procedimento permite manipular a nuvem de pontos de forma a ob- ter um posicionamento que melhor discrimine os diferentes grupos de espectros (Boardman \& Kruse, 1994). Esse tratamento proporciona uma melhor percepção dos agrupamentos de pontos permitindo uma separação e individualização das nuvens. Essa separação é feita manualmente por meio de uma ferramenta de desenho interativa em tela. Portanto, esse método consiste em um processo de classificação por identificação onde 0 analista define as classes. 0 conjunto de pontos selecionados em um grupo pode ser analisado por processos estatísticos definindo os valores de média, máximos e mínimos, entre outros. Esta etapa deve ser conduzida com cautela devido à possibilidade de conter espectros ruidosos. Por isso, o procedimento manual, onde 0 analista identifica os espectros, torna-se uma etapa prioritária apresentando vantagens com relação à utilização de métodos automatizados no presente caso.

\section{RESULTADOS \\ Resultados das propriedades espectrais do perfil de intemperismo}

As análises radiométricas das amostras foram realizadas considerando os principais horizontes presentes no perfil de intemperismo e o minério de manganês. Devido à exploração da mina é possível observar em superfícies esses diferentes horizontes.

\section{Horizonte ferruginoso}

As amostras do horizonte ferruginoso do perfil laterítico são caracterizadas pelos minerais: caulinita, gibbsita, goethita, hematita e quartzo. A relação entre esses minerais são muito estudados na análise espectroradiométria de solos tropicais (Epiphanio et al., 1992; Formaggio et al., 1996; Madeira Netto, 1991, 1996; Valeriano et al., 1995).

A caulinita apresenta feições duplas de absorção provenientes das vibrações moleculares das hidroxilas ( $\mathrm{OH}-$ ) em 1,4 $\mu \mathrm{m}$ e 
2,2 $\mu \mathrm{m}$ (Hlavay et al., 1977; Hunt et al., 1971, 1973; Hunt, 1980) ou mais precisamente em 1395/1495 e 2163/2208 (Crowley \& Vergo, 1988). Além disso, a caulinita possui uma fraca banda em 1,9 $\mu \mathrm{m}$ proveniente da ligação com a água (Hunt et al., 1971).

A gibbsita, de forma similar a caulinita, também apresenta feições de absorção diagnóstica provenientes das vibrações moleculares das hidroxilas em 1,55 $\mu \mathrm{m}$ e 2,3 $\mu \mathrm{m}$ (Hunt et al., 1971), sendo essa última também considerada em $2,265 \mu \mathrm{m}$ (Prost et al., 1983).

As feições típicas dos óxidos e hidróxido de ferro ocorrem no intervalo espectral do visível e infravermelho próximo entre $0,35 \mu \mathrm{m}$ até $1,5 \mu \mathrm{m}$ (Hunt \& Ashley, 1979). Essas feições diagnósticas são provenientes de transições eletrônicas de campo cristalino destacando-se na hematita a posição 0,885 $\mu \mathrm{m}$ e na goethita 0,917 $\mu \mathrm{m}$, (Sherman \& Waite, 1985). Morris et al. (1985) obtiveram valores similares em temperatura ambiente para as bandas do campo cristalino da goethita $(0,86 \mu \mathrm{m}) \mathrm{e}$ hematita $(0,91 \mu \mathrm{m})$. Desta forma, quando a ocorrência da feição de absorção ocorre em um comprimento de onda antes de $0,9 \mu \mathrm{m}$ é um indicativo que a hematita é o mineral predominante, em contraposição se 0 valor for superior que $0,9 \mu \mathrm{m}$ indica que a predominância é da goethita ou jarosita (Hunt \& Ashley, 1979). Devido a essas características, muitos estudos utilizam para a diferenciação entre os vários tipos de óxidos e hidróxidos de ferro a posição da banda do campo cristalino (Deaton \& Balsam, 1991; Kosmas et al., 1984, 1986; Malengreau et al., 1994, 1996; Scheinost et al., 1998). Outra importante característica espectral presente tanto na goethita como na hematita é a presença da transição do comportamento transparente-opaco, aproximadamente, em 0,55 $\mu \mathrm{m}$ (Hunt et al., 1971). Essa transferência de carga envolvendo a migração de elétrons do ferro para o oxigênio resulta em uma larga banda de absorção em comprimento de ondas inferiores que $0,55 \mu \mathrm{m}$, correspondendo a uma banda de condução (Hunt et al., 1971).

Deve-se salientar que o principal efeito da quantidade relativa de óxido e hidróxido de ferro é a variação da tonalidade do solo ou rocha na qual está contido, variando entre as cores amarelo, vermelho e marrom (Kosmas et al., 1986; Nagano et al., 1992, 1994; Torrent \& Schwertmann, 1987).

Desta forma, o comportamento espectral das principais unidades do horizonte ferruginoso (couraça e horizonte mosqueado) é caracterizado pela quantidade relativa dos minerais descritos (Fig. 5). A couraça mostra um predomínio de hematita em relação à goethita e menor quantidade de caulinita. Em contraposição 0 horizonte mosqueado apresenta espectros com maior presença de caulinita retratado pela maior profundidade da banda $\left(\mathrm{OH}^{-}\right)$e um predomínio da goethita em relação à hematita como descreve a feição de absorção do íon férrico.

\section{Saprólito argiloso}

0 saprólito, oriundo de ardósia e metassiltitos, caracteriza-se por conter uma alta porcentagem de argilominerais (illita, caulinita e gibbsita) e presença de óxido de ferro. Desta forma, as amostras do saprólito apresentam comportamento espectral similar às do horizonte ferruginoso, com feições de absorção mais pronunciadas referentes à hidroxila presentes nos minerais de argila (Fig. 6).

\section{Minério de manganês}

0 minério maciço de manganês é uma mistura de diferentes minerais, usualmente contendo psilomelano e pirolusita. As amostras de minério apresentam teores entre $50 \%$ a $63 \%$ de MnO. Freqüentemente, as amostras da mina Extrema apresentam-se associadas, em pequena proporção, a outros minerais argilosos, constatados pelo emprego da difratometria de raios- $X$ e análise química.

As curvas espectrais do minério de manganês apresentaram valores baixos de reflectância entre 10 a 22\%, caracterizados por comportamento linear e contínuo. Este comportamento típico dos minerais opacos é devido à presença da banda de condução onde os elétrons possuem maior energia que nas bandas de valência. Nessas bandas de condução os elétrons ficam livres para vagar através da malha cristalina, sendo denominados de elétrons livres ou de condução. Assim, os metais que exibem alta condutividade possuem abundância de elétrons livres, possuindo um intervalo de interrupção muito estreito ou não existente (Hunt, 1977). Uma abordagem simples e qualitativa para esse tipo de ligação metálica é o modelo do mar de elétrons. Nesse modelo, o retículo metálico é retratado como um arranjo regular de íons positivos "ancorados" em determinadas posições como bóias em um "mar" de elétrons móveis (Hunt, 1977). No caso do minério de manganês o comportamento espectral de baixa reflectância é proveniente do seu principal mineral o psilomelano que possui banda de condução relativa ao $\mathrm{MnO}_{3}$ que se estende por todo 0 intervalo espectral (Hunt et al., 1971).

Assim, os espectros das amostras são muito semelhantes variando apenas com a porcentagem de argila presente. A Figura 7 exemplifica um espectro do minério maciço e um com a presença de minerais de argila. A amostra com ausência de argilas, confirmados pela análise de difratometria de raios- $X$ e análise química (62,10\% de Mn0), possui um comportamento retilíneo com valores de reflectância em torno de 15\%. Em contraposição a amostra 


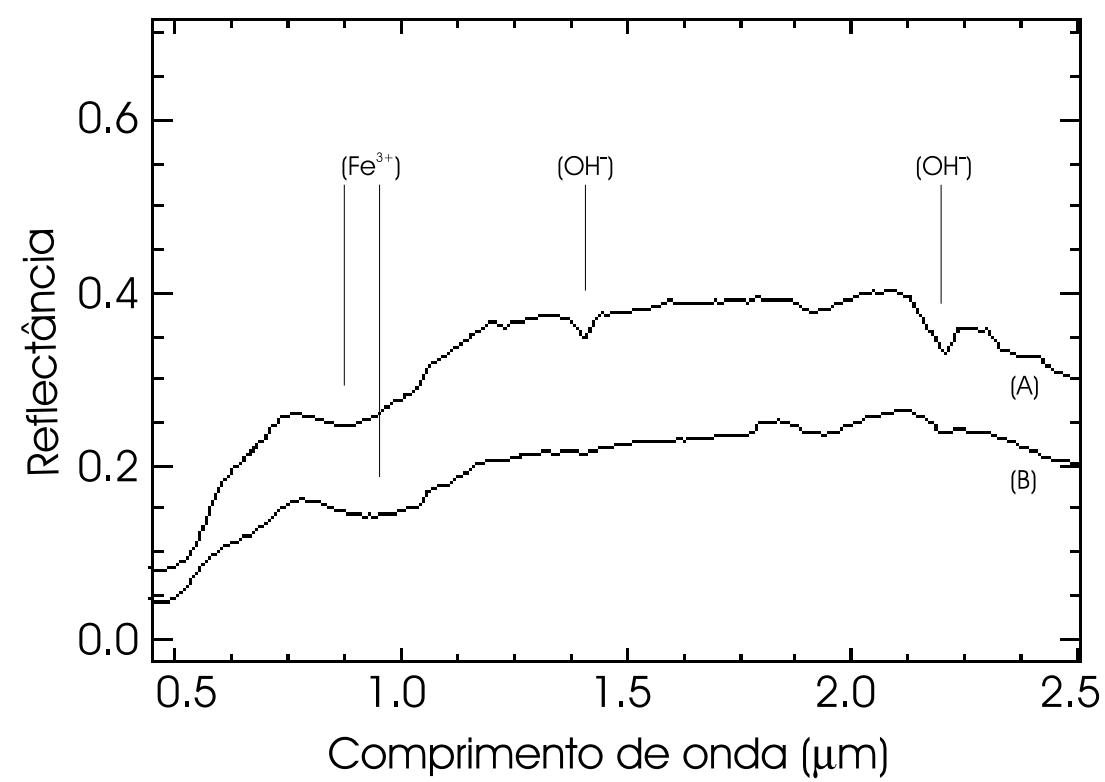

Figura 5 - Comportamento espectral de amostras presentes no horizonte ferruginoso: (A) horizonte mosqueado e (B) couraça.

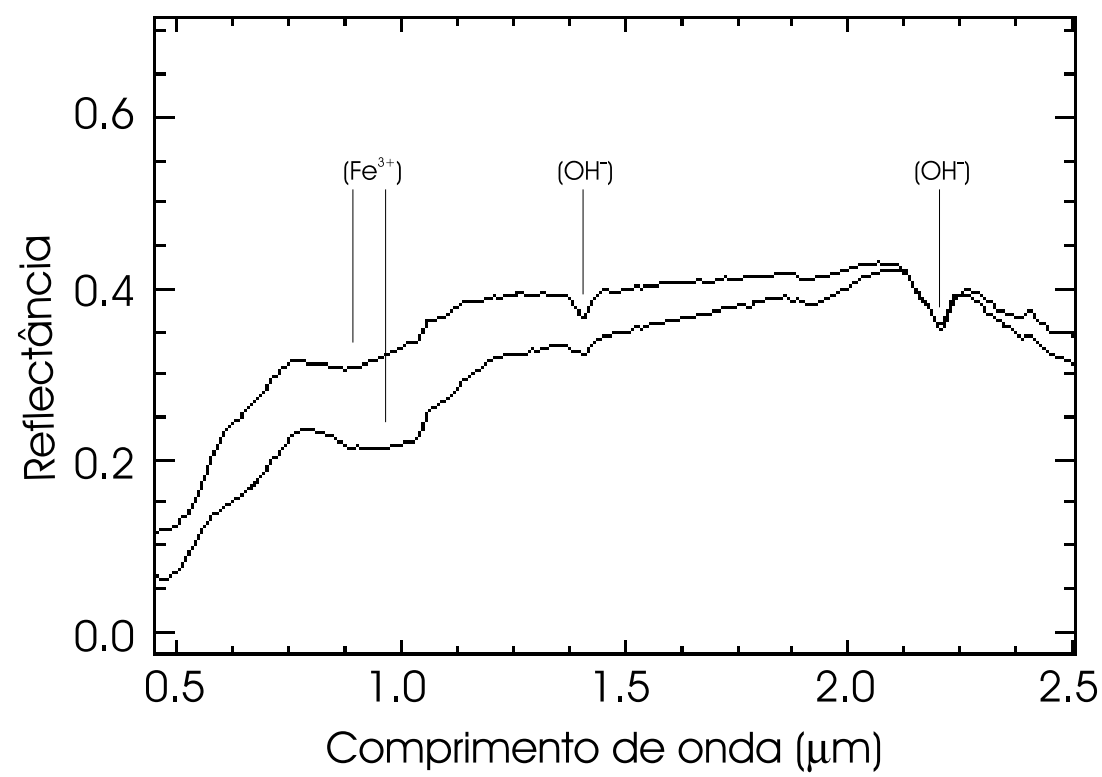

Figura 6 - Comportamento espectral de amostras do saprólito.

com a presença de minerais argilosos, detectados na difratometria de raios- $X$ e geoquímica, demonstra um espectro que apresenta uma ligeira subida dos valores de reflectância de $0.4 \mu \mathrm{m}$ até $1.1 \mu \mathrm{m}$ quando se torna constante até $2.5 \mu \mathrm{m}$.

Um importante aspecto da presença dos minerais de manganês é a sua influência quando misturado com outros minerais. 0 comportamento de uma mistura espectral é proveniente da integração de dois ou mais componentes distintos que geram um comportamento espectral híbrido de seus integrantes. Desta forma, o espectro de uma mistura é uma combinação das reflectâncias dos membros puros ou finais presentes. Pode-se distinguir dois tipos de mistura com comportamentos distintos: a mistura macroscópica e a mistura microscópica ou mistura íntima. A mistura íntima apresenta uma distribuição aleatória 
e um espalhamento múltiplo da luz entre as espécies minerais (Jonhson et al., 1983; Mustard \& Pieters, 1989). Nessas condições é preponderante o espalhamento interpartícula que intensifica 0 efeito de absorção da luz. Na mistura íntima 0 comportamento espectral não é uma função linear dos seus constituintes sendo mais influenciada pelos componentes de baixo albedo (Johnson et al., 1983).

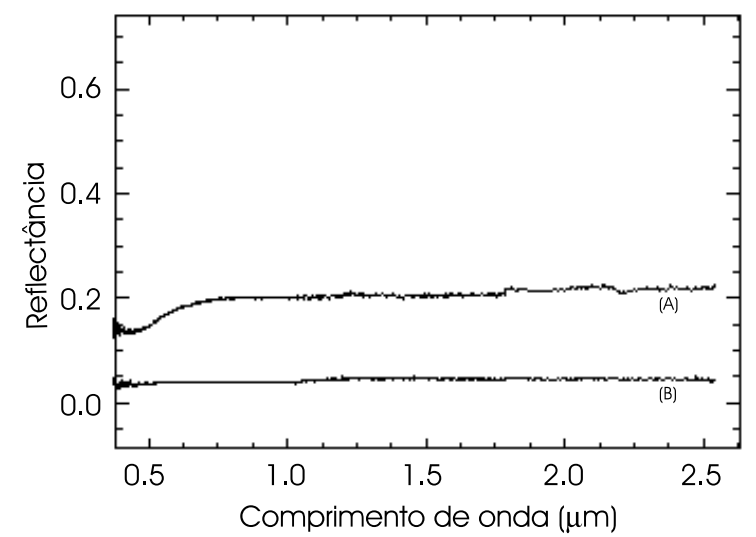

Figura 7 - Curvas espectrais do minério de manganês da mina Extrema: (A) minério com a presença de minerais de argila e (B) minério sem a presença de minerais de argila.

Portanto, no presente estudo das assembléias minerais observa-se que pequenas proporções de psilomelano são eficientes para reduzir o albedo das curvas espectrais. Esses resultados são consistentes com estudos prévios referentes às misturas íntimas de minerais opacos e não opacos (Carvalho Júnior et al., 2004; Nash \& Conel, 1974; Singer, 1981; Madeira Netto, 1991).

A Figura 8 apresenta uma série de espectros, com os seus respectivos difratogramas de raios- $X$, relativas às amostras do perfil laterítico com aumento gradativo de minerais de manganês. Essa série apresenta variações de assembléias minerais referentes às encaixantes do minério contendo minerais como goethita, hematita, caulinita, gibbsita e quartzo até a amostra do minério de manganês constituído principalmente de psilomelano e pirolusita. 0 comportamento espectral de uma amostra é resultante da mistura espectral dos minerais presentes.

\section{Resultados do processamento digital da imagem hiperespectral}

A metodologia desenvolvida estabelece uma série de restrições que permite aprimorar a seleção de espectros relativos à presença de minerais opacos e prováveis áreas de minas abandonadas. Devido às características espectrais do minério de manganês, com baixa reflectância e ausência de feição espectral, observa-se dificuldades para separá-lo de outros alvos como áreas sombrea- das e corpos de água, entre outros. Portanto, são estabelecidos três procedimentos para selecionar e distinguir esses espectros suprimidos: (a) cálculo da integral do espectro, (b) índice espectral para separar áreas sombreadas com cobertura vegetal, e (c) identificação manual utilizando a transformação MNF e o visualizador $n$-dimensional do programa ENVI.

Primeiramente, o cálculo da integral do espectro seguido do fatiamento permitiu selecionar áreas de baixa reflectância com maior probabilidade da presença de óxido de manganês em superfície (Fig. 9). No entanto, essa metodologia para a área de estudo apresentou dificuldades para separar áreas de mineração com as porções sombreadas.

0 índice proposto com a integral do espectro modificada mostrou-se adequado permitindo excluir as localidades que não são de interesse, uma vez que as áreas sombreadas da imagem em estudo estão em posições de relevo íngreme e com cobertura vegetal e sem uso da terra (Fig. 10).

Apesar do índice proposto permitir uma individualização das áreas de minério 0 emprego de técnicas de seleção manual de espectros mostra-se mais preciso. A metodologia consiste na análise da variação espectral utilizando a transformação MNF seguida por uma identificação manual utilizando 0 visualizador $n$-dimensional. A partir do emprego do MNF sobre as áreas de baixo albedo pode-se segmentar três grupos: área mineralizada de manganês, áreas de sombra e áreas de vegetação sombreada. A Figura 11 apresenta um diagrama de dispersão da primeira componente MNF contraposta a segunda componente. A partir deste diagrama pode-se individualizar na imagem os três grupos com características espectrais distintas (Fig. 12). Desta forma é possível melhor destacar a área relativa à mina Extrema em relação aos demais alvos possivelmente existente.

\section{CONCLUSÃO}

A área da mina da Fazenda Extrema possui um perfil laterítico constituído pelo horizonte ferruginoso, saprólito argiloso e 0 minério de manganês que ocorre disperso no saprólito como grãos, seixos, matacões e bloco. 0 comportamento espectral das amostras do perfil laterítico do horizonte ferruginoso e do saprólito é caracterizado pelas feições de vibrações moleculares das hidroxilas ( $\mathrm{OH}-$ ) presentes na gibbsita e caulinita e pelas feições de transiçõos eletrônicas de campo cristalino $\left(\mathrm{Fe}^{+3}\right)$ presentes nos óxidos e hidróxido de ferro. 0 minério de manganês possui uma curva espectral com baixa reflectância, devido à banda de condução do $\mathrm{MnO}_{3}$, sem a existência de feições diagnósticas de absorção. 

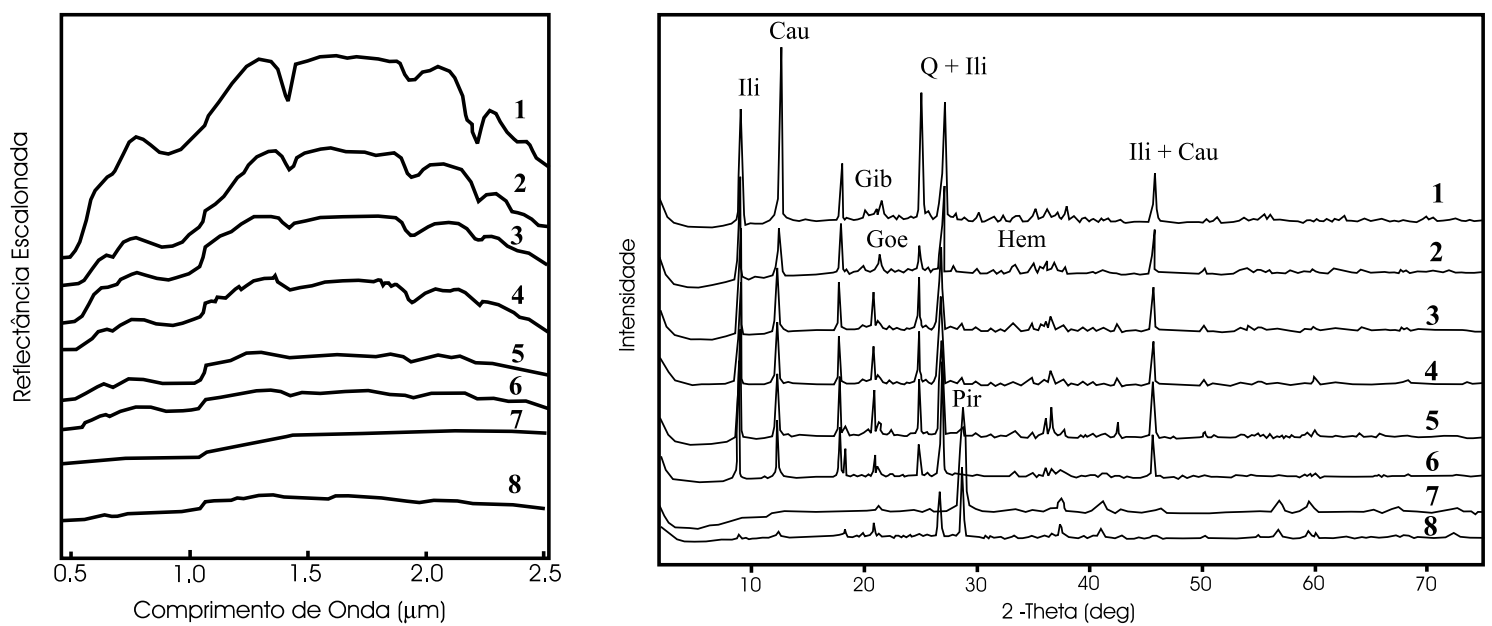

Figura 8 - Comportamento espectral de amostras referentes à mina Extrema e seu respectivo difratômetro de raios-X. Os nomes dos minerais apresentam-se abreviados: ilita (lli), caulinita (Cau), gibbsita (Gib), quartzo (Q), hematita (Hem), Goethita (Goe) e Pirolusita (Pir).
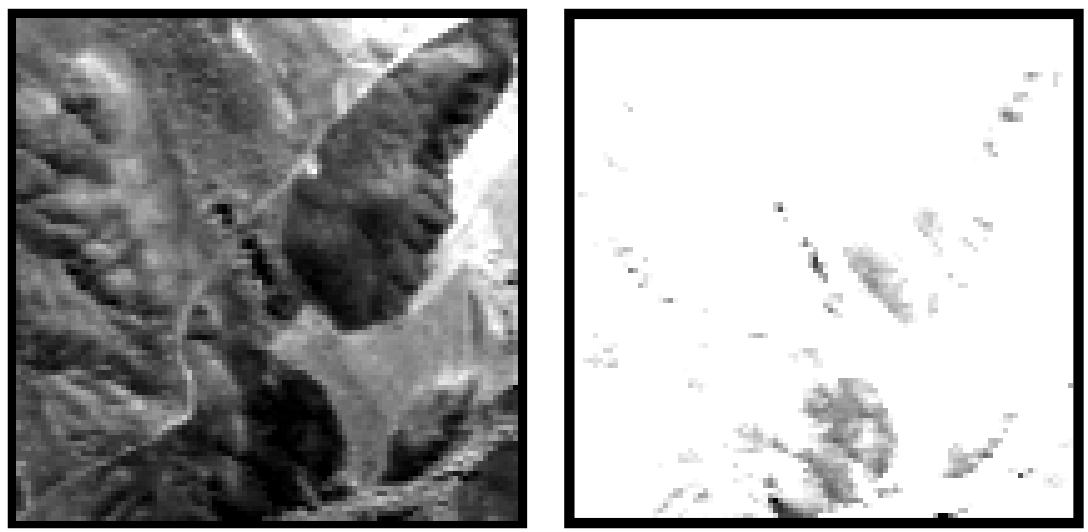

Figura 9 - Imagens provenientes do cálculo da integral do espectro e sua respectiva imagem fatiada separando os valores de baixa reflectância.
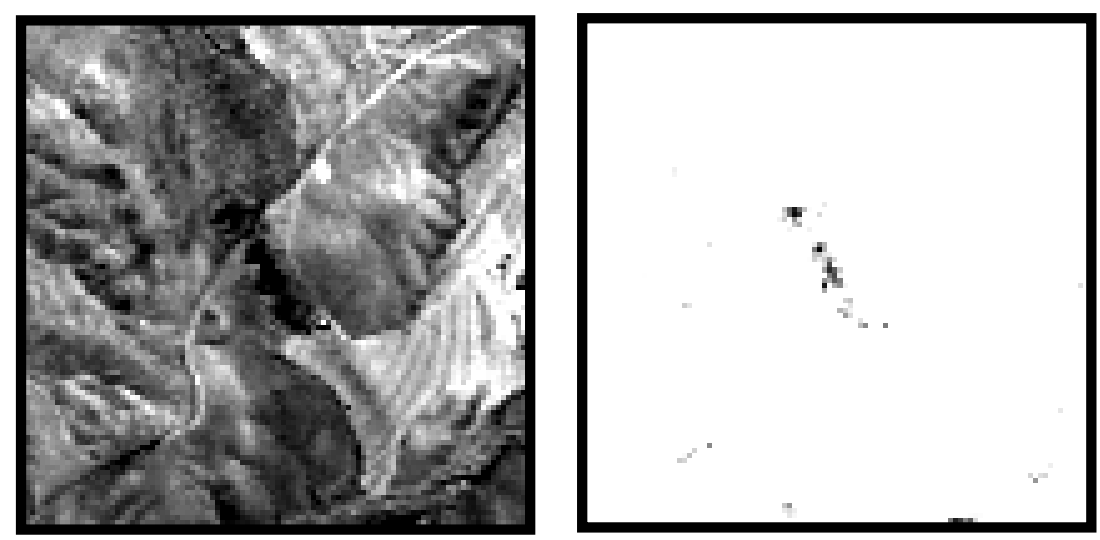

Figura 10 - Imagens referentes ao cálculo da integral do espectro modificada e a imagem correspondente ao fatiamento dos dados mais baixos. 
Desta forma, a principal característica para a individualização dos minérios de manganês laterítico por espectrometria de imageamento é 0 comportamento de baixa reflectância dos seus minerais. Assim, a metodologia proposta realiza uma pré-seleção de alvos pelo cálculo da integral do espectro, complementada por uma análise espectral para distinção de outros elementos de baixa reflectância. Desta forma, foram abordados os seguintes procedimentos: (a) cálculo da integral do espectro, (b) índice espectral para separar áreas sombreadas com cobertura vegetal, e (c) identificação manual utilizando a transformação MNF e o visualizador $n$-dimensional.

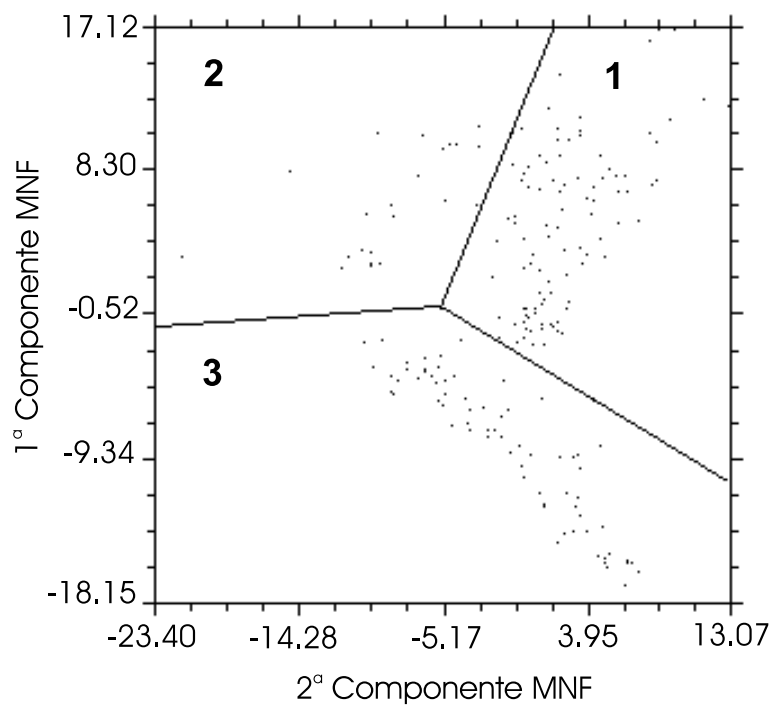

Figura 11 - Diagrama de dispersão entre a $1^{\mathrm{a}}$ e $2^{\mathrm{a}}$ componente MNF permitindo a separação de três grupos: 1 - mina de manganês; 2 - áreas sombreadas e 3 - áreas de vegetação com sombreamento.

0 procedimento proposto individualizou a área da mina Extrema que foi explorada e agora se encontra abandonada. Devido à baixa regeneração essas áreas exploradas ficam expostas, sem cobertura vegetal o que facilita e torna mais eficiente a sua detecção. Este procedimento permite identificar as áreas afetadas pela atividade mineral e que não tiveram nenhum procedimento para sua recuperação. 0 cadastro destas áreas é importante para a estruturação de um plano para a recuperação ambiental da região.

\section{REFERÊNCIAS}

ANDERSON GP, WANG J \& CHETWYND JH. 1995. MODTRAN3: An update and recent validations against airborne high-resolution interferometer measurements. Summaries of the Annual JPL Airborne Earth Science Workshop, 5, Pasadena, CA, JPL Publ. 95-1, 5-8.

BAÊTA JÚNIOR JDA, MARTINS EG, LEITE EA, RAMOS JB, SÁ JAG, RIBEIRO MB \& PIRES PRO. 1978. Projeto Manganês no Centro-Sul de Goiás. Relatório Final, DNPM/CPRM. Escala 1:50.000.
BERK A, BERNSTEIN LS \& ROBERTSON DC. 1989. MODTRAN: A moderate resolution model for LOWTRAN7. Final report, GL-TR-0122, AFGL, Hanscomb AFB, MA, $42 p$.

BOARDMAN JW \& KRUSE FA. 1994. Automated spectral analysis: A geologic example using AVIRIS data, north Grapevine Mountains, Nevada. Proceedings of the ERIM Tenth Thematic Conference on Geologic Remote Sensing, 10, Environmental Research Institute of Michigan, Ann Arbor, MI., 407-418.

CARVALHO JÚNIOR OA \& MENESES PR. 2000. Spectral Correlation Mapper (SCM): an improving Spectral Angle Mapper. Proceedings of the JPL Airborne Earth Science Workshop, 9, Pasadena, CA, JPL Publ. 00-18, 65-74.

CARVALHO JÚNIOR OA, LATORRE M, DIAS LAV, CARVALHO APF, GUIMARÃES RF \& MENESES PR. 2002a. Comparação dos métodos Green e ATREM para correção atmostérica de imagens hiperespectrais AVIRIS. Espaço \& Geografia, 5(1): 179-197.

CARVALHO JÚNIOR OA, CARVALHO APF, MENESES PR \& GUIMARÃES RF. 2002b. Classificação e eliminação dos rúídos em imagens hiperespectrais pela análise seqüencial da transformação por fração de ruído mínima. Revista Brasileira de Geofísica, 20(1): 31-41.

CARVALHO JÚNIOR OA, MARTINS ES, CARVALHO APF, MENESES PR, GUIMARÃES RF \& CARDOSO FBF. 2004. Cálculo da abundância de minerais de depósito de níquel da Mina Fazenda por espectroradiometria. Revista Brasileira de Geociências, São Paulo, 34(4): 579-586.

CLARK RN \& SWAYZE GA. 1995. Mapping minerals, amorphous materials, environmental materials, vegetation, water, ice and snow, and other materials: the USGS Tricorder algorithm. Summaries of the Annual JPL Airborne Earth Science Workshop, 5, Pasadena, CA, JPL Publ. 95-1, 39-40.

CROWLEY JK \& VERGO N. 1988. Near-infrared reflectance spectra of mixtures of kaolin-group minerals; use in clay mineral studies. Clays and Clay Minerals, 36(4): 310-316.

DARDENNE MA. 1979. Les Minéralizations de Plomb, Zinc, fluor du Protérozoique Superior dans Le Brésil Central. Avec une mise au point sur la chronologie du Précambrien brésilien. Thèse de Doctorat, d'Etat, Université de Paris VI. Paris. 251 p.

DEATON BC \& BALSAM WL. 1991. Visible spectroscopy: a rapid method for determining hematite and goethite concentration in geological materials. Journal of Sedimentary Petrology, 61: 628-632.

ENVI. The Environment for Visualizing Images. 1997. Tutorials better solutions. Colorado: Consulting Limited Liability Company Lafayette, $370 \mathrm{p}$.

EPIPHANIO JCN, FORMAGGIO AR, VALERIANO MM \& OLIVEIRA JB. 1992. Comportamento espectral de solos do Estado de São Paulo. São José dos Campos: INPE, $134 \mathrm{p}$. 

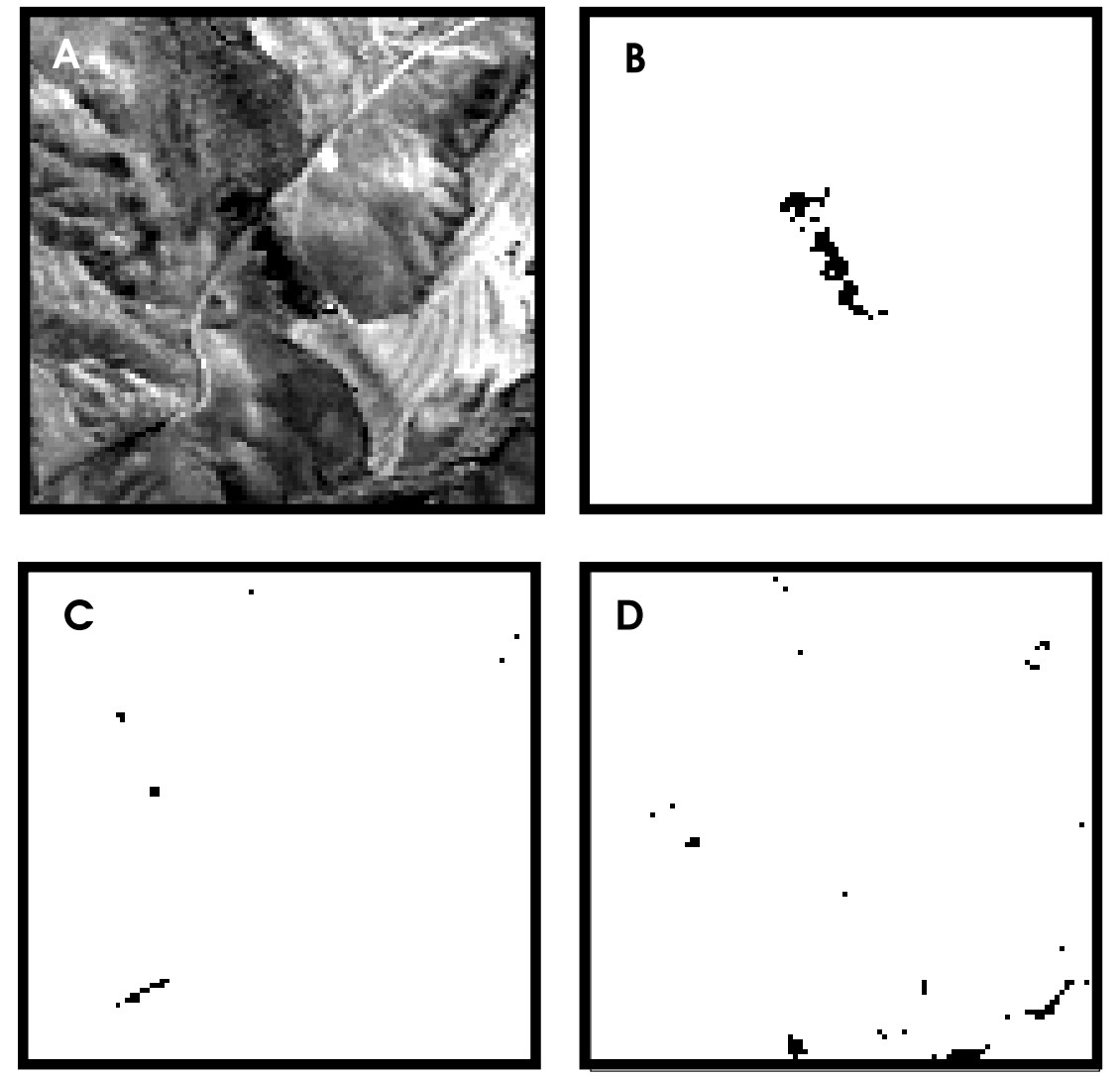

Figura 12 - As imagens relativas aos grupos delimitados pela técnica MNF: (A) imagem da integral do espectro modificada; (B) mina de manganês; (C) área sombreada e (D) área de vegetação com sombreamento.

FARIA A. 1995. Estratigrafia e Sistemas Deposicionais do Grupo Paranoá nas Áreas de Cristalina, Distrito Federal e São João D’Aliança Alto Paraíso de Goiás. Tese (Doutorado em Geologia), Universidade de Brasília. Brasília. 199 p.

FORMAGGIO AR, EPIPHANIO JCN, VALERIANO MM \& OLIVEIRA JB. 1996. Comportamento espectral $(450-2.450 \mathrm{~nm})$ de solos tropicais de São Paulo. Revista Brasileira de Ciência do Solo, 20: 467-474.

GAO B-C, HEIDEBRECHT KB \& GOETZ AFH. 1993. Derivation of scaled surface reflectances from AVIRIS data. Remote Sensing of Environment, 44: 165-178.

GREEN AA, BERMAN M, SWITZER P \& CRAIG MD. 1988. A transformation for ordering multispectral data in terms of images quality with implications for noise removal: IEEE Transactions on Geoscience and Remote Sensing, 26(1): 65-74.

GREEN RO. 1990. Retrieval of reflectance from calibrated radiance imagery measured by the Airborne Visible/Infrared Imaging Spectrometer (AVIRIS) for lithological mapping of Clark Mountains, California. Proceedings of the Airborne Visible/Infrared Imaging Spectrometer (AVIRIS) Workshop, 2, Pasadena, CA, JPL Publ. 90-54, 167-175.
GREEN RO, CONEL JE, MARGOLIS JS, BRUEGGE J \& HOOVER GL. 1991. An inversion algorithm for retrieval at atmospheric and leaf water absorption from AVIRIS radiance with compensation for atmospheric scattering. Summaries of the Annual JPL Airborne Visible/Infrared Imaging Spectrometer (AVIRIS) Workshop, 3, Pasadena, CA, JPL Publ. 91-28, 51-61.

GREEN RO, CONEL JE \& ROBERTS DA. 1993. Estimation of aerosol optical depth, and additional atmospheric parameters for the calcuIation of apparent reflectance from radiance measured by the airborne visible/infrared imaging spectrometer. Summaries of the Annual JPL Airborne Earth Science Workshop, 4, Pasadena, CA, JPL Publ. 93-26, 83-86.

GREEN RO, EASTWOOD ML, SARTURE CM, CHRIEN TG, ARONSON M, CHIPPENDALE BJ, FAUST JA, PAVRI BE, CHOVIT CJ, SOLIS M, OLAH MR \& WILLIAMS 0. 1998. Imaging spectroscopy and the Airborne Visible/Infrared Imaging Spectrometer (AVIRIS). Remote Sensing of Environment, 65: 227-248.

GUIMARÃES EM. 1978. Os Depósitos de Manganês de S. João D’Aliança - G0. Dissertação (Mestrado em Geologia), Universidade de Brasília, Brasília, 129 p. 
HLAVAY J, JONAS K, ELEK S \& INCZEDY J. 1977. Characterization of the particle size and crystallinity of certain minerals by infrared spectrophotometry and other instrumental methods: I. Investigations on clay minerals. Clays and Clay Minerals, 25: 451-456.

HUNT GR. 1977. Spectral signature of particulate minerals in the visible and near infrared. Geophysics, 42(3): 401-413.

HUNT GR. 1980. Electromagnetic radiation: The communication link in remote sensing. In: SIEGAL BS \& GILLESPIE AR (Ed.). Remote sensing in geology. New York: John Wiley. p. 5-45.

HUNT GR \& ASHLEY RP. 1979. Spectra of altered rocks in the visible and near infrared. Economic Geology, 74: 1613-1629.

HUNT GR, SALISBURY JW \& LENHOFF CJ. 1971. Visible and near infrared spectra of minerals and rocks: III. Oxides and hydroxides. Modern Geology, 3: 195-205.

HUNT GR, SALISBURY JW \& LENHOFF CJ. 1973. Visible and near infrared spectra of minerals and rocks: VI. Additional silicates. Modern Geology, 4: 85-106.

JOHNSON PE, SMITH MO, TAYLOR-GEORGE S \& ADAMS JB. 1983. A semi-empirical method for analysis of the reflectance spectra of binary mineral mixtures. Journal of Geophysical Research, 88: 3557-3561.

KAUFMAN YJ, HOBBS PV, KIRCHHOFF VWJH, ARTAXO P, REMER LA, HOLBEN BN, KING MD, WARD DE, PRINS EM, LONGO KM, MATTOS LF, NOBRE CA, SPINHIRNE JD, JI O, THOMPSON AM, GLEASON JF, CHRISTOPHER SA \& TSAY S-C. 1998. Smoke, Clouds, and Radiation-Brazil (SCAR-B) experiment. Journal of Geophysical Research, 103(D24): 31.783-31.808.

KOSMAS CS, CURL N, BRYANT RB \& FRANZMEIER DP. 1984. Characterization of iron oxide minerals by second-derivative visible spectroscopy. Soil Science Society America Journal, 48: 401-405.

KOSMAS CS, FRANZMEIER DP \& SCHULZE DG. 1986. Relationship among derivative spectroscopy, color, crystallite dimensions, and $\mathrm{Al}$ substitution of synthetic goethites and hematites. Clays and Clay Minerals, 34: 625-634.

KRUSE FA, LEFKOFF B \& DIETZJB. 1993a. Expert system-based mineral mapping in northern Death Valley, California/Nevada, using the Airborne Visible/Infrared Imaging Spectrometer (AVIRIS), Remote Sensing of Environment, 44: 309-336.

KRUSE FA, LEFKOFF AB, BOARDMAN JW, HEIEDBRECHT KB, SHAPIRO AT, BARLOON PJ \& GOETZ AFH. 1993b. The Spectral Image Processing System (SIPS) - interactive visualization and analysis of imaging spectrometer data. Remote Sensing of Environment, 44: 145-163.

LATORRE MF. 1998. Utilização de um método de correção atmosférica para o processamento de dados hiperespectrais do sensor AVIRIS em regiões tropicais. Dissertação (Mestrado em Sensoriamento Remoto),
Instituto Nacional de Pesquisas Espaciais (INPE), São José dos Campos, $176 \mathrm{p}$.

LEE JB, WOODYATT AS \& BERMAN M. 1990. Enhancement of high spectral resolution remote sensing data by a noise - adjusted principal components transform. IEEE Transactions on Geoscience and Remote Sensing, 28(3): 295-304.

MADEIRA NETTO JS. 1991. Étude quantitative des relations constituants minéralogiques-réflectance diffuse des latosols brésiliens. Application a I'utilisation pédologique des données satellitaires TM (région de Brasília). Thèse de Doctorat, Université Pierre et Marie Curie. Paris. 224 p.

MADEIRA NETTO JS. 1996. Spectral reflectance properties of soils. Photogra Interpretation, 34: 59-70.

MALENGREAU N, BEDIDI A, MULLER J-P \& HERBILLON AJ. 1996. Spectroscopic control of iron oxide dissolution in two ferralitic soils. European Journal of Soil Science, 47: 13-20.

MALENGREAU N, MULLER J-P \& CALAS G. 1994. Fe-speciation in ka0lins: A diffuse reflectance study. Clays and Clay Minerals 42: 137-147.

MELFI AJ, TRESCASES JJ, CARVALHO A, OLIVEIRA SMB, RIBEIRO FILHO E \& FORMOSO MLL. 1988. The lateritic ore deposits of Brazil. Sciences Geologiques Bulletin, France, 41: 5-36.

MORRIS RV, LAUER HV Jr, LAWSON CA, GIBSON EK Jr, NACE GA \& STEWART C. 1985. Spectral and other physicochemical properties of submicron powders of hematite (alpha- $\mathrm{Fe}_{2} \mathrm{O}_{3}$ ), maghemite (gamma$\mathrm{Fe}_{2} \mathrm{O}_{3}$ ), magnetite $\left(\mathrm{Fe}_{3} \mathrm{O}_{4}\right)$, goethite (alpha- $\mathrm{FeOOH}$ ), and lepidocrocite (gamma-Fe00H). Journal of Geophysical Research, 90(B4): 3126-3144.

MUSTARD JF \& PIETERS CM. 1989. Photometric phase functions of common geologic minerals and applications to quantitative analysis of mineral mixture reflectance spectra. Journal of Geophysical Research, 94(B10): 13.619-13.634.

NAGANO T, NAKASHIMA S, NAKAYAMA S, OSADA K \& SENOO M. 1992. Color variations associated with rapid formation of goethite from protoferrihydrite at $\mathrm{pH} 13$ and $40^{\circ} \mathrm{C}$. Clays and Clay Minerals, 40: 600-607.

NAGANO T, NAKASHIMA S, NAKAYAMA S \& SENOO M. 1994. The use of color to quantify the effects of $\mathrm{pH}$ and temperature on the crystallization kinetics of goethite under highly alkaline conditions. Clays and Clay Minerals, 42: 226-234.

NASH DB \& CONEL JE. 1974. Spectral reflectance systematics for mixtures of powdered hypersthene, labradorite, and ilmenite. Journal of Geophysical Research, 79: 1615-1621.

PROST R, KING C \& LEFEBVRE D'HELLENCOURT T. 1983. Propriétés de réflexion diffuse de pâtes de kaolinite en fonction de leur teneur en l'eau. Clay Minerals, 18: 193-204.

RAJESH HM. 2004. Application of remote sensing and GIS in mineral resource mapping - An overview. Journal of Mineralogical and Petrological Sciences, 99(3): 83-103. 
SCHEINOST AC, CHAVERNAS A, BARRON V \& TORRENT J. 1998. Use and limitations of second-derivative diffuse reflectance spectroscopy in the visible to near-infrared range to identify and quantify Fe oxide minerals in soils. Clays and Clay Minerals, 46(5): 528-536.

SHERMAN DM \& WAITE TD. 1985. Electronic Spectra of Fe3+ oxides and oxide hydroxides in the near IR to near UV. American Mineralogist, 70: $1.262-1.269$.

SINGER RB. 1981. Near-infrared reflectance of mineral mixtures: Systematic combinations of pyroxenes, olivine, and iron oxides. Journal of Geophysical Research, 86: 7967-7982.

TORRENT J \& SCHWERTMANN U. 1987. Influence of hematite on the color of red beds. Journal of Sedimentary Petrology, 57: 682-686.

VALERIANO MM, EPIPHANIO JCN, FORMAGGIO AR \& OLIVEIRA JB. 1995. Bi-directional reflectance factor of 14 soil classes from Brazil. International Journal of Remote Sensing, 16: 113-128.

VANE G \& GOETZ AFH. 1988. Terrestrial imaging spectrometry. Remote Sensing of Environment, 24: 1-29.

VANE G, CHRISP M, ENMARK H, MACENKA S \& SOLOMON J. 1984. Airborne Visible/Infrared Imaging Spectrometer (AVIRIS): an advanced tool for earth remote sensing. Proceedings of the IEEE International Geoscience and Remote Sensing Symposium, New York, SP215, 751-757.

\section{NOTAS SOBRE OS AUTORES}

Osmar Abílio de Carvalho Júnior. Recebeu o título de geólogo pela Universidade de Brasília em 1990, e de mestre e doutor em prospecção mineral pela Universidade de Brasília em 1995 e 2000, respectivamente. Trabalhou como Pesquisador do Instituto Nacional de Pesquisas Espaciais (INPE) entre 2002 e 2004 . Atualmente é professor da Universidade de Brasília e bolsista de produtividade e pesquisa do CNPq onde realiza pesquisas sobre o processamento digital de imagens multiespectrais e hiperespectrais.

Múcio Nobre da Costa Ribeiro. Obteve a graduação em Geologia pela Universidade de Brasília, UNB. Realizou o mestrado em processamento de dados em geologia e análise ambiental pela Universidade de Brasília em 2005. Atualmente trabalha na FUNAl, onde realiza trabalhos de análise ambiental e geoprocessamento.

Éder de Souza Martins. Obteve a graduação em Geologia pela Universidade de Brasília, UNB, em 1987. Realizou o mestrado em 1991 e doutorado 1999 ambos em Geologia pela Universidade de Brasília. Atualmente trabalha na Empresa Brasileira de Pesquisa Agropecuária, Centro de Pesquisa Agropecuária dos Cerrados, CPAC onde coordena o laboratório de pedologia. Realiza pesquisa em metodologias para o mapeamento e generalização cartográfica de informações pedológicas.

Edi Mendes Guimarães. Obteve a graduação em Geologia pela Universidade de Brasília (1973), mestrado em Geologia pela Universidade de Brasília (1978) e doutorado em Geologia pela Universidade de Brasília (1997). Atualmente é professora adjunta da Universidade de Brasília. Tem experiência na área de Geociências, com ênfase em Sedimentologia, atuando principalmente nos seguintes temas: difratometria de raios-X, ambientes de sedimentação, Grupo Paranoá, microssonda eletrônica e argilominerais

Paulo Roberto Meneses. Obteve a graduação em Geologia pela Universidade de Brasília (1973), mestrado em Sensoriamento Remoto pelo Instituto Nacional de Pesquisas Espaciais (1977) e doutorado em Geociências (Geoquímica e Geotectônica) pela Universidade de São Paulo (1986). Atualmente é professor associado da Universidade de Brasília. Tem experiência na área de Geociências, com ênfase nos seguintes temas aplicados à geologia: sensoriamento remoto, geoprocessamento, fotointerpretação, hiperespectral e espectrorradiometria.

Renato Fontes Guimarães. Recebeu o título de engenheiro cartógrafo pela Universidade do Estado do Rio de Janeiro em 1987, 0 grau de mestre em geofísica pelo Observatório Nacional em 1991 e o grau de doutor em geologia pela Universidade Federal do Rio de Janeiro em 2000. Atualmente é professor Adjunto do Departamento de Geografia e chefe do Laboratório de Sistemas de Informações Espaciais do Departamento de Geografia da Universidade de Brasília. Possui como principais linhas de pesquisa o sensoriamento remoto e a modelagem matemática dos processos erosivos. É bolsista de produtividade e pesquisa do CNPq. 